\title{
INNERVATION OF THE HEART OF PRAUNUS FLEXUOSUS (MYSIDACEA)
}

\author{
By J. S. Alexandrowicz \\ The Plymouth Laboratory
}

(With Plate I and Text-fig. I)

The heart nerves of Praunus flexuosus Leach (=Macromysis flexuosa White) have been stained with methylene blue applied in various ways. As a rule the animals were injected with a solution prepared immediately before use by mixing I part of $0.5 \%$ solution of methylene blue in distilled water or of rongalit white with two parts of sea water. The injection was made into one of the posterior segments of the abdomen with the needle pointing forwards. When three or four animals are treated at the same time, usually in at least one of them the staining reaction takes a satisfactory course and its progress can be observed under the microscope, owing to the transparency of the tissues. In a few minutes after the injection some of the nerves are already visible. Later the coloration becomes more general and more intensive, but soon begins to fade out and can disappear completely.

For staining the heart nerves by a second procedure, i.e. by immersion in a weak solution of the dye, the animals should be sectioned along the ventral side and their digestive organs and gonads taken out. It is, moreover, necessary to remove the large chromatophores situated on the ventral side of the pericardial diaphragm, and this membrane has also to be pulled out. The heart thus becomes exposed with its ventral wall uppermost, which can be cut along the middle line to give better access to the main trunks of the heart nerves situated on its dorsal side. The same way of exposing the heart has to be followed when the preparations obtained by the method of injection are to be fixed, as the ammonium molybdate solution does not penetrate through the chitin.

The fixation of the staining caused the same difficulties as experienced with amphipods (Alexandrowicz, 1954). It is obvious that in these animals the bond between the dye and the stainable substance of nerves is of a very unstable nature, and only at the moment when the coloration attains the peak of its intensity the fixation may give somewhat more satisfactory results. It is difficult to estimate this right moment, especially as various nerve elements may take up the dye at different times. Thus, for instance, the nerve cells in the heart of Praunus stain but rarely and always later than the fibres. By waiting too long for their possible appearance many otherwise good preparations are lost. 


\section{OBSERVATIONS}

The heart of Mysidacea situated in the thoracic region has a shape of a fusiform tube continuing forwards and backwards into the anterior and posterior aorta respectively, the only vessels which can be seen from the dorsal side (Text-fig. I A). As stated by Delage (I883) the limits of the heart tube, which at its ends does not differ in width from these vessels, can be determined by the presence of the valves. It may be added that the muscle fibres of the heart do not pass on to the arteries and therefore the places where they stop mark the boundaries of the heart. The muscle fibres, of finely crossstriated type, are arranged in a single layer. They turn in right-handed spirals as in the Isopoda, whereas in the Amphipoda the direction is reversed.

From the ventral side of the heart arise several arteries. The largest of them, the sternal artery, originates at a certain distance from the posterior aorta and a little to the left of the middle line. The two hepatic arteries arise close to each other and to the anterior aorta. According to Delage there are, in addition, two unpaired arteries originating between the hepatic and the sternal arteries: the anterior of them, which as this writer remarks is very slender, could not be recognized in methylene-blue preparations.

\section{Nerves of the Heart}

The three systems of nerves observed in the heart of all Malacostraca investigated up to now have been also found in the Mysidacea. There are: (I) a local system made up of neurons situated in the heart itself, (2) nerves connecting the local system with the central nervous system, and ( 3 ) nerves of the arterial valves.

\section{Local System}

The main elements of the local system are situated on the outside of the dorsal heart wall. A short trunk, lying just in front of the ostia and bifurcating at each end, forms a characteristic figure with the branches resulting from these divisions (Text-fig. I A; P1. I, fig. I). The two anterior and the two posterior trunks, running in opposite directions, and traceable up to the ends of the heart, give off many branches, the largest of them passing on to the ventral side of the heart.

The ganglion cells, the axons of which make up these trunks, number no less than six. Two of them are situated near the posterior end of the unpaired main trunk, and four on the anterior trunks, two on each of them (Text-fig. I A, g.c.; cf. the photograph, P1. I, fig. 3, on which four of the cells are seen). Their situation can vary; the middle pair can lie nearer or farther from the main trunk, but the most anterior ones have always been found far forwards approximately midway between the ostia and the anterior end of the heart. The cells usually look as if they were unipolar; only rarely some dendritic 


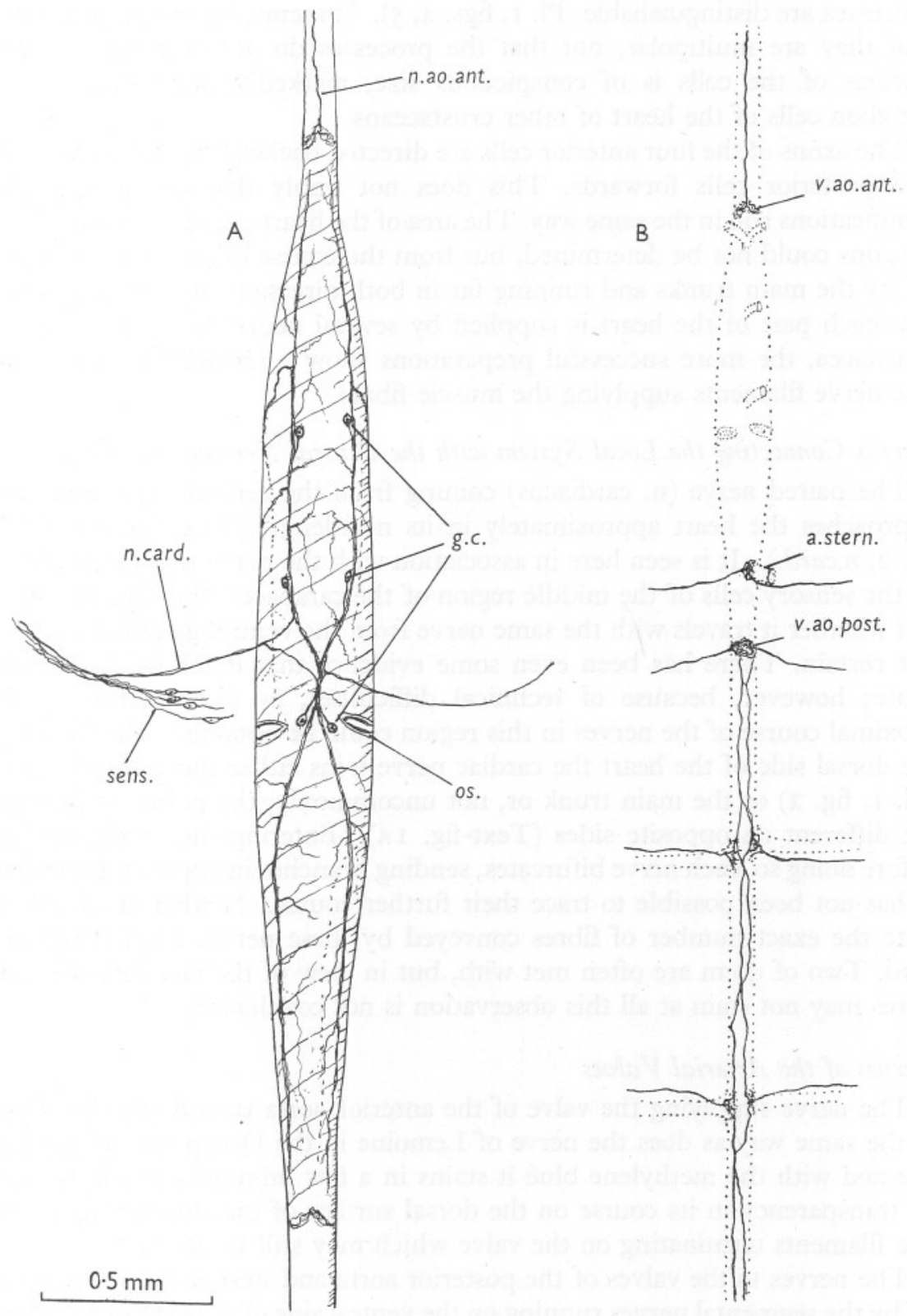

Text-fig. I, A: Praunus flexuosus. View of the heart from the dorsal side showing the main nerve trunks and their branches. g.c., ganglion cells; n.card., cardiac nerve; sens., sensory nerve cells; n.ao.ant., nerve of the valve of the anterior aorta; os., ostium. $\mathrm{B}$ : nervous system of the arterial valves. The heart is seen from the ventral side. v.ao.ant., valve of the anterior aorta; v.ao.post., valve of the posterior aorta; a.stern., sternal artery. 
processes are distinguishable (P1. I, figs. 4, 5). It seems, however, more likely that they are multipolar, but that the processes do not stain clearly. The nucleus of the cells is of conspicuous size, markedly larger than in the ganglion cells of the heart of other crustaceans.

The axons of the four anterior cells are directed backwards, and those of the two posterior cells forwards. This does not imply that all their further ramifications run in the same way. The area of the heart supplied by individual neurons could not be determined, but from the course of the branches given off by the main trunks and running far in both directions it may be inferred that each part of the heart is supplied by several neurons. As usual in the Crustacea, the more successful preparations show a remarkable richness of fine nerve filaments supplying the muscle fibres.

\section{Nerves Connecting the Local System with the Central Nervous System}

The paired nerve (n. cardiacus) coming from the central nervous system approaches the heart approximately in its mid-length (Text-fig. I A; Pl. I, fig. 2 , n.card.). It is seen here in association with the nerve that carries fibres of the sensory cells of the middle region of the carapace (Text-fig. I A, sens.), but whether it travels with the same nerve from the ventral ganglionic cord is not certain. There has been even some evidence that it follows a different route; however, because of technical difficulties, no clear picture of the proximal course of the nerves in this region could be obtained. Passing on to the dorsal side of the heart the cardiac nerve joins either the anterior trunks (P1. I, fig. 2) or the main trunk or, not uncommonly, the points of junction are different on opposite sides (Text-fig. IA). Entering the trunk, or even before doing so, each nerve bifurcates, sending branches in opposite directions. It has not been possible to trace their further course. Neither am I able to state the exact number of fibres conveyed by these nerves from the neural cord. Two of them are often met with, but in view of the fact that the finer fibres may not stain at all this observation is not conclusive.

\section{Nerves of the Arterial Valves}

The nerve supplying the valve of the anterior aorta runs down this vessel in the same way as does the nerve of Lemoine in the Decapoda. In animals injected with the methylene blue it stains in a few minutes and can be seen by transparency in its course on the dorsal surface of the stomach up to the fine filaments terminating on the valve which may still be active.

The nerves to the valves of the posterior aorta and sternal artery are given off by the segmental nerves running on the ventral side of the extensor muscles and therefore can be visible only after dissection of the animals. They do not stain so readily as in the anterior aorta and can be but rarely noticed, the more so that during various manipulations described above the fine nerves can be easily torn away. Maybe for the same reason I was unable to trace the nerves 
to the remaining four arteries arising on the ventral side of the heart. On the other hand, it has been easy to observe the innervation of the posterior aorta in its course down the abdomen. This vessel, called also abdominal artery, is supplied in each segment by fine nerves running along its segmental branches. These nerves give off two sorts of fibres: some, very short, end at the origin of the segmental paired vessels; others run alongside the abdominal artery establishing connexions of the whole system including the valve at the posterior end of the heart. The arrangement is strikingly similar to that found in decapods (Alexandrowicz, I929, I932), and it seems highly probable that this sytem of nerves in mysids is also destined to supply the valves at the exit points of the segmental arteries in the abdomen, although the latter could not be clearly seen in Praunus.

\section{DisCUSSION}

The recorded results provide another proof, that, in the Crustacea, various components of the heart innervation follow one fundamental pattern. The differences observed appear to be rather of minor character. As regards the local system in mysids its peculiar feature, compared with amphipods and isopods, is the arrangement in pairs of the ganglion cells and their situation at a certain distance from the middle line, whereas in the two other groups all cells lie in the unpaired median trunk. The number of cells (six) found in Praunus is the same as stated for Ligia oceanica (Alexandrowicz, I952) and assumed to be the most probable in Marinogammarus marinus (Alexandrowicz, I954). However, rather than to admit that this coincidence be not a fortuitous one, I am bound to express doubts whether the number found in Praunus is correct. For one reason, it is surprising that the posterior part of the heart, about half of its total length, should be deprived of nerve cells. In various crustaceans with an elongated heart such as the Amphipoda, Isopoda and Stomatopoda, ganglion cells are present along the whole of its length, and in the Decapoda it is in the posterior half that the ganglionic trunk, or the major part of it, is located. Also, in view of the symmetrical disposition of the main trunks in mysids, the presence of the cells in the posterior trunks could be expected. The negative results may be due to the insufficient staining of cells in this region. Moreover, owing to the deeper situation of the posterior part of the heart, it is much less accessible to observation by transparency which has been otherwise very helpful.

As regards the nerves connecting the local system with the central nervous system it must be pointed out that only one pair of them has been noticed in mysids, whereas in amphipods two such paired nerves and in stomatopods even three are present. Perhaps in mysids as in decapods the cardiac nerve conveys fibres of different kind and origin, but, as mentioned before, its proximal course could not be determined. On the other hand, it is not certain 
whether there is really only one pair of the cardiac nerves. With animals of such a small size nerves made up of very tiny fibres may not show at all.

It is possible for this reason that I could not detect the nerves on the pericardial diaphragm which, as in other crustaceans, might be expected to supply the muscle fibres of the pericardium. It is true that such muscle fibres were not observed, but this again may be due to the short-comings of the technical methods.

Uncertainty also remains regarding the occurrence of the pericardial organs, i.e. nerves of special structure which have been found in the Decapoda, Stomatopoda and Amphipoda. In Praunus there are nerve elements which in their arch-like arrangement resemble the pericardial organs in Leander serratus (see Alexandrowicz, 1953). However, because of their insufficient staining and even more because of their small dimensions, their nature could not be established. It is to be hoped that with species of larger size this point, as well as others mentioned above, might be satisfactorily elucidated.

\section{SUMMARY}

In the heart of Praunus flexuosus three systems of nerve elements have been found. The local system consists of no less than six neurons. Their cell-bodies are situated on the dorsal heart wall near the short unpaired trunk and its two anterior branches. The axons of the nerve cells innervate the muscle fibres of the heart. A pair of cardiac nerves joining the trunks of the local system establish the connexion with the central nervous system. A separate set of nerves supplies the valves of the vessels arising from the heart. The nerves of the valve of the posterior aorta are connected with the nerves running alongside this vessel which receive segmental branches coming from the abdominal ganglia.

\section{REFERENCES}

Alexandrowicz, J. S., I929. Badania nad unerwieniem serca raka (Potamobius astacus). Recherches sur l'innervation du coeur de l'Ecrevisse (Potamobius astacus). Folia Morph., Warsz., Vol. I, pp. 37-68. [Polish with French abstract.]

- 1932. The innervation of the heart of the Crustacea. I. Decapoda. Quart. F. micr. Sci., Vol. 75, pp. I8I-249.

- I952. Innervation of the heart of Ligia oceanica. F. Mar. biol. Ass. U.K., Vol. 31, pp. 85-96.

- 1953. Nervous organs in the pericardial cavity of the decapod Crustacea. F. Mar. biol. Ass. U.K., Vol. 31, pp. 563-580.

- I954. Innervation of an amphipod heart. F. Mar. biol. Ass. U.K., Vol. 33, pp. 709-719.

DeLAGE, Y., I883. Circulation et respiration chez les Crustacés Schizopodes (Mysis Latr.). Arch. zool. exp. gén., T. I, pp. 106-130. 

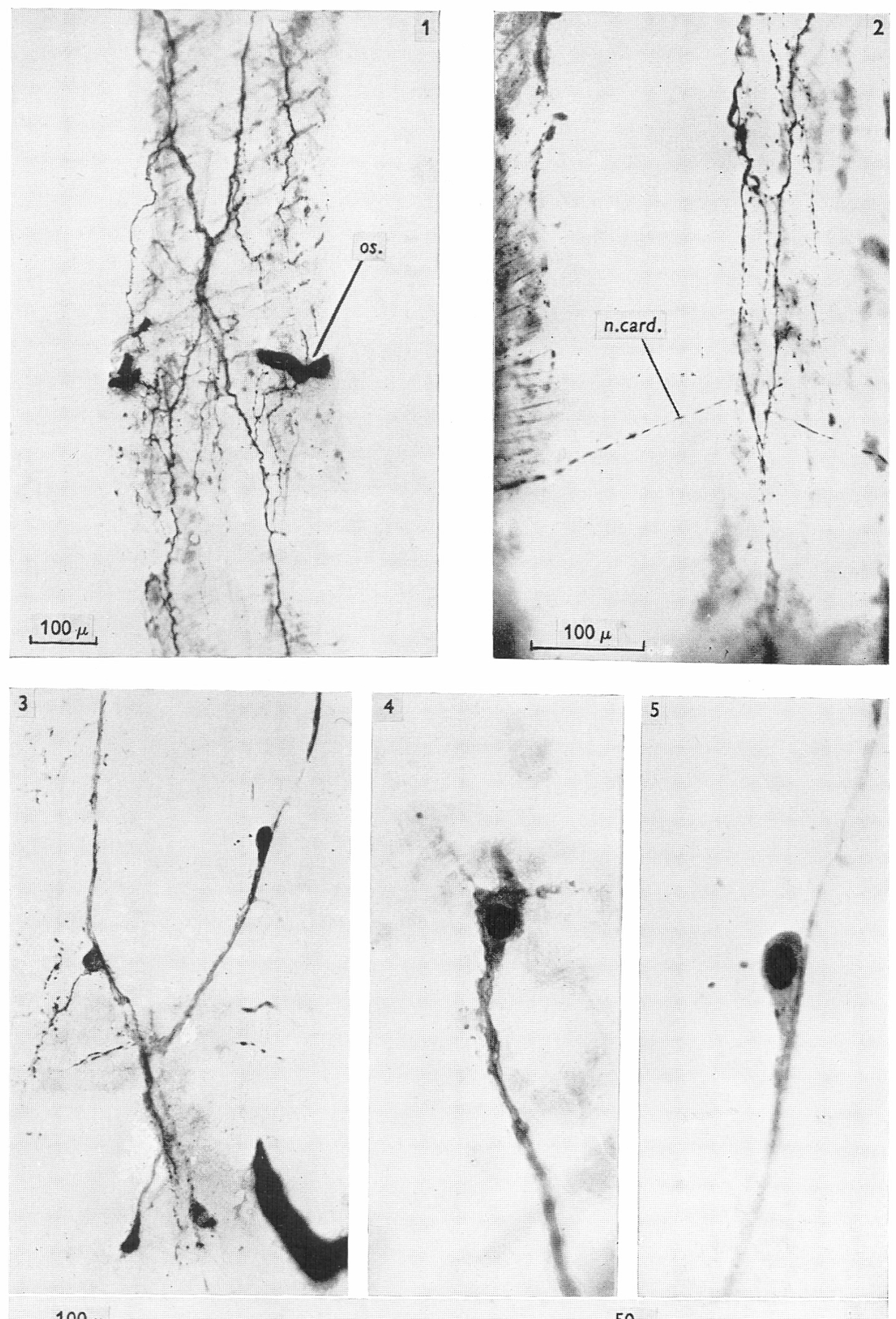

$100 \mu$ 


\section{EXPLANATION OF PLATE I}

All photomicrographs have been made from preparations of the heart of Praunus flexuosus stained with methylene blue, fixed in ammonium molybdate and mounted in dammar-xylol. Fig. I. Middle part of the heart with main nerve trunks and some of their branches. Ganglion cells and cardiac nerves are not visible. os., ostium.

Fig. 2. Middle part of the heart with main trunks and cardiac nerves (n.card) entering the anterior trunks. The position of the anterior trunks close to each other is due to elongation of the heart produced artificially.

Fig. 3. Middle and posterior pair of ganglion cells.

Fig. 4. Anterior ganglion cell.

Fig. 5. Middle ganglion cell. Note the size of the nucleus. 